\title{
Synthesis and Photochromic Properties of Unsymmetry Diarylethene1-[2-methyl-5- (4-n-amyl-phenyl)-3-thienyl]-2-[2-methyl-1-phenyl] Perfluorocyclopentene
}

\author{
Fen Xu , Xiaodong Zhang, Xiaorong Dong, \& Gang Liu* \\ Jiangxi Key Laboratory of Organic Chemistry \\ Jiangxi Science and Technology Normal University, \\ Nanchang 330013, P. R. China \\ e-mail:liugang0926@163.com
}

\begin{abstract}
An unsymmetrical photochromic diarylethene, 1-[2methyl-5-(4-n-amyl-phenyl)-3-thienyl]-2-[2-methyl-1-phenyl] perfluorocyclopentene (10), has been synthesized. Its photochromic properties were examined. The results showed that this compound exhibited reversible photochromism and undergo reversible cyclization and cycloreversion reactions upon alternating irradiation with $U V$ and visible light in solution.
\end{abstract}

\section{Keywords-diarylethene; photochromism; fluorescence}

\section{INTRODUCTION}

Photochromism, a photoinduced reversible reaction between two isomers, is one of the essential photochemical reactions to facilitate the reversible fluorescence switching process in synthetic molecules [1-3]. Photochromic diarylethenes are considered to be among the most promising systems for applications in optical memory media and switching devices due to their excellent photochromic properties coupled with thermal stability, fatigue resistance, and sensitivity [4-6]. To the best of our knowledge, only a few publications concerning the substituent position effect on the optoelectronic properties of diarylethenes have been published [7,8]. Previously, the focus has been on the effect of electron-withdrawing groups, such as fluorine or chlorine atoms, and it has been found that these halide substituents and their positions have a significant effect on the properties of the diarylethene compounds $[9,10]$.

In this work, an unsymmetrical photochromic diarylethene, 1-[2-methyl-5-(4-n-amyl-phenyl)-3-thienyl]-2[2-methyl-1-phenyl]perfluorocyclopentene (10) was synthesized and its photochemical properties were investigated in detail. 1o exhibited good photochromism and fluorescence in acetonitrile. The photochromic reaction of diarylethene 1o is shown in Scheme 1.
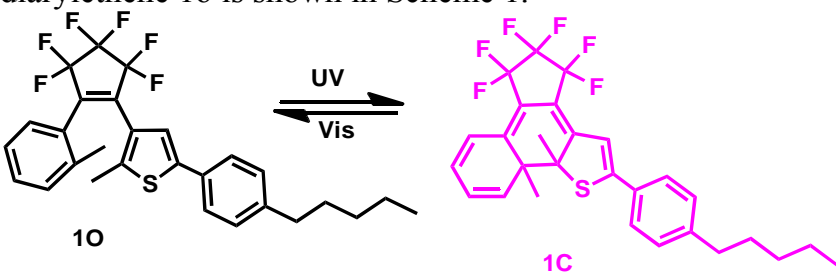

Scheme 1. Photochromism of diarylethene 10 by light

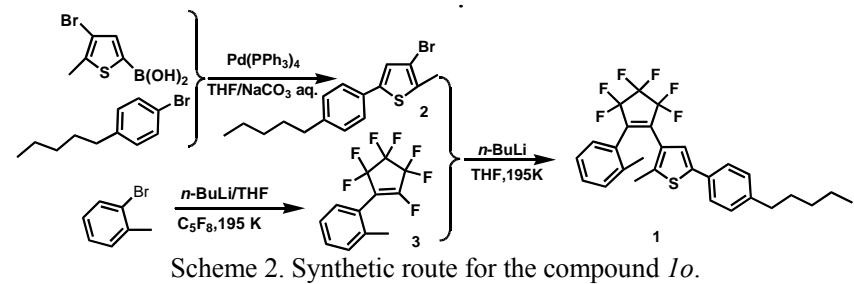

\section{EXPERIMENTS}

Synthesis of diarylethene 1 . The synthetic route for 10 was shown in Scheme 2. It was synthesized according to the similar procedure $\mathrm{Pu}$ et al. Under an argon gas atmosphere, compound 2 was dissolved in THF and n-butyl lithium hexane solution was added at $195 \mathrm{~K}$. Stirring was continued for $30 \mathrm{~min}$ at this low temperature, then compound 3 was added and the mixture was stirred for $1 \mathrm{~h}$ at this low temperature. Then through purified by column chromatography on silica gel (petroleum ether) [11]. The structure of compound 1o was confirmed by ${ }^{1} \mathrm{H}$ NMR (400 $\left.\mathrm{MHz}, \mathrm{CDCl}_{3}, \mathrm{TMS}\right): \delta 0.89\left(\mathrm{~m}, 3 \mathrm{H}, \mathrm{CH}_{3}\right), 1.32(\mathrm{~m}, 2 \mathrm{H}$, $\left.\mathrm{CH}_{2}\right), 1.61\left(\mathrm{~m}, 2 \mathrm{H}, \mathrm{CH}_{2}\right), 1.94(\mathrm{~s}, 1 \mathrm{H}$, thieny, $\mathrm{lH}), 1.98(\mathrm{~m}$, $\left.2 \mathrm{H}, \mathrm{CH}_{2}\right), 2.48(\mathrm{~s}, 1 \mathrm{H}$, thieny, $\mathrm{lH}), 2.58\left(\mathrm{~m}, 2 \mathrm{H}, \mathrm{CH}_{2}\right), 7.36$ (m, $2 \mathrm{H}$, pheny, $\mathrm{lH}), 7.45(\mathrm{~m}, 2 \mathrm{H}$, pheny, $\mathrm{lH})$.

\section{RESUlts AND Discussion}

\section{A. Photochromism of 10.}

Figure 1 shows the absorption spectral and color changes of 1 in acetonitrile $\left(2.0 \times 10^{-5} \mathrm{~mol} \mathrm{~L}^{-1}\right)$ induced by alternating irradiation with UV and visible light. The unsymmetrical diarylethene 1o exhibits good photochromic properties and can switch between its colorless ring-open and deep pink ring-closed forms with appropriate wavelengths of light in acetonitrile. The absorption maximum of 10 was observed at $284 \mathrm{~nm}$ Figure 1. Upon irradiation with $297 \mathrm{~nm}$ light, the colorless solution of 10 turned to pink (Figure 1), in which the absorption maximum was observed at $539 \mathrm{~nm}$ emerged due to the formation of closed-ring isomer 1c. Reversely, the solution of $1 \mathrm{c}$ could be completely bleached upon irradiation with visible light $(\lambda>500 \mathrm{~nm})$. 


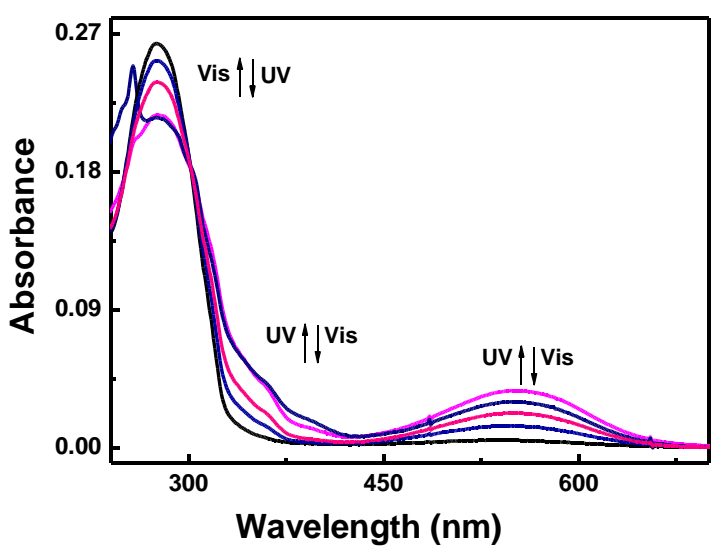

Figure 1. Absorption spectral and color change of 10 in acetonitrile $(2.0 \times$ $\left.10^{-5} \mathrm{~mol} \mathrm{~L}^{-1}\right)$.

\section{B. Photochromic reaction kinetics in acetonitrile solution.}

The photochromic cyclization/cycloreversion kinetics of 1 in acetonitrile were determined by UV-Vis spectra upon alternating irradiation with UV and appropriate wavelength visible light at room temperature. The cyclization and cycloreversion curves of 1 were shown in Figure 2. It can be seen that the relationships between the absorbance and exposal time have good linearity upon irradiation with 297 $\mathrm{nm}$ UV light demonstrating that the cyclization process of 10 belongs to the zeroth order reaction when open-ring isomer changed to closed-ring isomer.

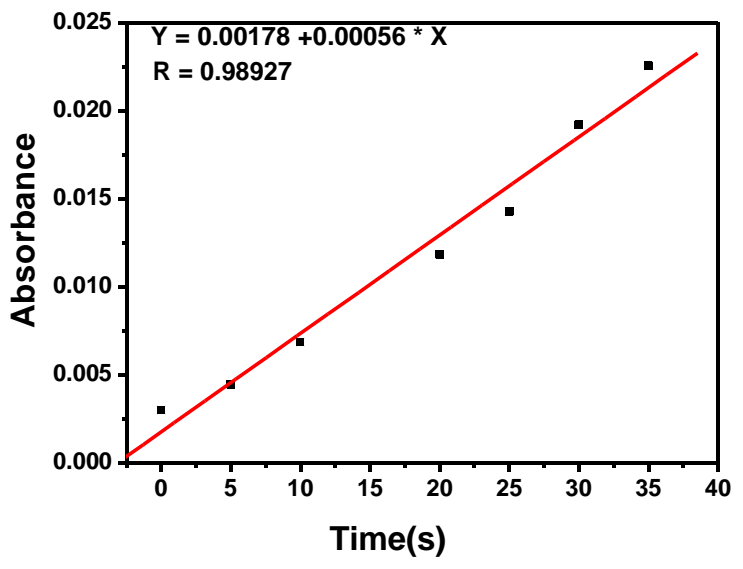

(a)

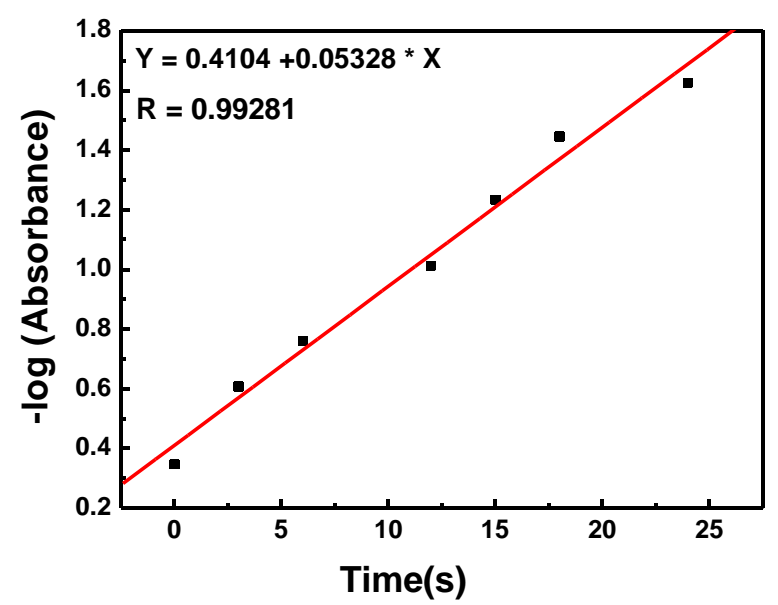

(b)

Figure 2. The cyclization/cycloreversion kinetics of 10 in acetonitrile (2.0 $\left.\times 10^{-5} \mathrm{~mol} \mathrm{~L}^{-1}\right)$.

\section{Fluorescence of 10.}

The fluorescence properties of 10 in acetonitrile were measured. Figure 3 showed the fluorescence spectral changes of 10 in acetonitrile solution upon irradiation with $297 \mathrm{~nm}$ light at room temperature. As shown in Figure. 3, the fluorescence emission peak at $371 \mathrm{~nm}$ upon irradiation with $297 \mathrm{~nm}$ UV light. The fluorescence intensity decreased along with the photochromism from open-ring isomers to closedring isomers upon irradiation with $297 \mathrm{~nm}$ UV light.

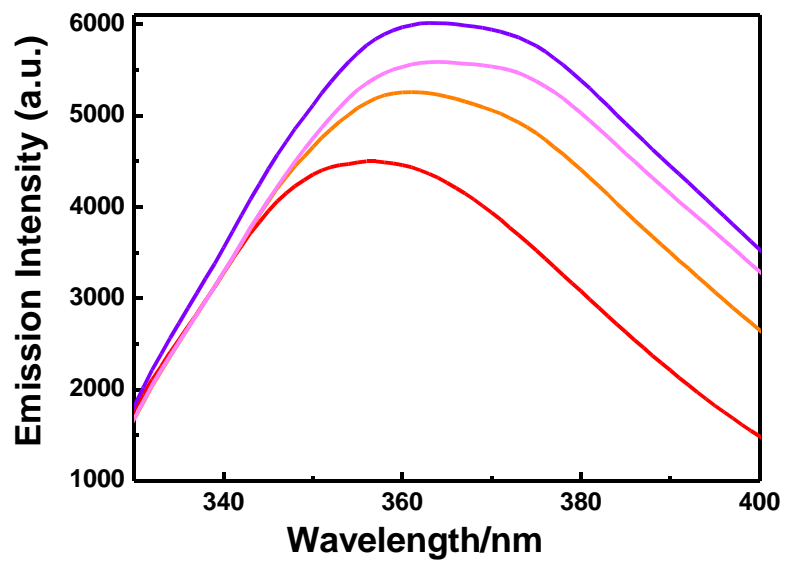

Figure 3. Fluorescent intensity changes of 10 in acetonitrile.

\section{SUMmary}

In conclusion, an unsymmetrical photochromic diarylethene was synthesized and its photochromic and kinetics properties were investigated. The diarylethene exhibited excellent photochromic and fluorescent switching behaviors with distinctive color changes. The photochromic reaction kinetics in solution was studied too. Their cyclization/cycloreversion processes belong to the 
zeroth/first order reaction in hexane. The results will be helpful in designing and the synthesis of new photochromic diarylethene systems with tunable photochromic characteristic for further potential application in optoelectronic devices.

\section{ACKNOWLEDGEMENT}

The authors are grateful for the financial support from the National Natural Science Foundation of China (21262015) and the Masters' Innovative Foundation of Jiangxi Science and Technology Normal University (YC2014-X03).

\section{REFERENCES}

[1] M. Russew, and S. Hecht, "Photoswitches: From Molecules to Materials," Adv Mater., Vol. 22, 2010, pp. 3348-3360, doi: 10.1002/adma.200904102.

[2] Q.S. Wei, and A. Wei, "Optical Imaging with Dynamic Contrast Agents," Chem. Eur. J., vol. 17, 2011, pp. 1080-1091, doi: 10.1002/chem.201002521.

[3] M. Irie, "Diarylethenes for memories and switches," Chem. Rev., vol. 100, 2000, pp. 1685-1716, doi: 10.1021/cr980069d.

[4] A. Bianco, and S. Perissinotto, "Control of optical properties through photochromism: a promising approach to photonics," Laser \&
Photonics Rev., vol.5, 2011, pp. 711-736, doi: 10.1002/lpor.201000033.

[5] M.Irie, "Organic chemistry: a digital fluorescent molecular photoswitch," Nature, vol. 420, 2002, pp. 759-760, doi: $10.1038 / 420759$ a.

[6] S. Kobatake, and S. Imao, "Photoswitching of an alcohol-sensitive photochromic diarylethene," Tetrahedron Lett., vol. 52, 2011, pp. 1905-1908, doi: 10.1016/j.tetlet.2011.02.039.

[7] H. Tian and J.Y. Song. "Recent progresses on diarylethene based photochromic switches," Chemical Society Reviews., vol. 33. 2, 2004, pp. 85-97, doi: 10.1039/B302356G.

[8] A. Bianco, and C. Bertarelli, "Diarylethenes with Electroactive Substituents: A Theoretical Study to Understand the Effect on the IR Spectrum and a Simple Way to Read Optical Memory in the Mid-IR," Chem. Mater., vol. 17, 2005, pp. 869-874, doi: 10.1021/cm048729k.

[9] S.Z. Pu, and T.S. Yang, " Substituent position effect on the optoelectronic properties of photochromic diarylethenes," Tetrahedron Lett., vol. 47, 2006, pp. 3167-3171, doi: 10.1016/j.tetlet.2006.02.124.

[10]C.B. Fan, "Substituent position effect on the properties of isomeric photochromic diarylethenes bearing chlorine atoms," Journal of Photochemistry and Photobiology A: Chemistry, vol. 194, 2008, pp. 333-343, doi: 10.1016/j.jphotochem.2007.08.032.

[11] S.Z. Pu, and L.S. Yan, "Synthesis and chlorine atom position effect on the properties of unsymmetrical photochromic diarylethenes," J. Photochem, Photobiol, vol. 196, 2008, pp. 84-93, doi: 10.1021/ol070622q. 